\title{
Toward a Third Culture: Being in between
}

\author{
Victoria Vesna
}

Leonardo, Vol. 34, No. 2. (2001), pp. 121-125.

Stable URL:

http://links.jstor.org/sici?sici=0024-094X\%282001\%2934\%3A2\%3C121\%3ATATCBI\%3E2.0.CO\%3B2-3

Leonardo is currently published by The MIT Press.

Your use of the JSTOR archive indicates your acceptance of JSTOR's Terms and Conditions of Use, available at

http://www.jstor.org/about/terms.html. JSTOR's Terms and Conditions of Use provides, in part, that unless you have obtained prior permission, you may not download an entire issue of a journal or multiple copies of articles, and you may use content in the JSTOR archive only for your personal, non-commercial use.

Please contact the publisher regarding any further use of this work. Publisher contact information may be obtained at http://www.jstor.org/journals/mitpress.html.

Each copy of any part of a JSTOR transmission must contain the same copyright notice that appears on the screen or printed page of such transmission.

The JSTOR Archive is a trusted digital repository providing for long-term preservation and access to leading academic journals and scholarly literature from around the world. The Archive is supported by libraries, scholarly societies, publishers, and foundations. It is an initiative of JSTOR, a not-for-profit organization with a mission to help the scholarly community take advantage of advances in technology. For more information regarding JSTOR, please contact support@jstor.org. 


\section{Toward a Third Culture: Being In Between}

\section{Victoria Vesna}

Practice must always be founded on sound theory.

-Leonardo Da Vinci [1]

Artists working with computer and other technologies from the scientific world are also often informed and inspired by the exciting innovations and discoveries taking place in science. We are also keenly interested in what cultural critics and commentators in the humanities have to say about the meaning of these discoveries and innovations and their impact on culture and society. Scientists can relate to and understand our work easily primarily because we use the same tools-computers. Because our work and tools are in constant flux, we are forced to articulate the reasoning and meaning informing the art we produce, which has traditionally been the role of art critics and historians. This creates room for an active dialogue with both humanists and scientists. Thus we are placed in between these "Two Cultures," which creates a triangle and promises the emergence of a third culture. This is both a privileged and a dangerous position, at least at this transitional stage. Therefore it is important to take a look at the background and current status of the two-cultures concept.

\section{THE GHOST OF C.P. SNOW PERSISTS}

Much of the discussion concerning the triangle of art, science and technology can be traced back to C.P. Snow's famous Rede lecture at Cambridge on 7 May 1959, "The Two Cultures and the Scientific Revolution." The idea of "two cultures" inspired a cultural discussion that has endured remarkably long. Snow identified the two cultures as those of literary intellectuals and natural scientists, and he pointed to the curricula of schools and universities as the source of the problem. In his introduction to Snow's subsequent book based on the lecture [2], Stephan Collini gave a historical perspective to this divide by locating its beginning in the Romantic period, at the turn of the nineteenth century. He then traced the genealogy of Britain's "two-cultures" anxiety in the linguistic peculiarity by which the term "science" came to be used in a narrowed sense, referring only to the "physical" or "natural" sciences.

The compilers of the Oxford English Dictionary recognized that this was a fairly recent development, with no example given before the 1860s: "We shall . . . use the word 'science' in the sense which the Englishmen so commonly give it; as expressing physical and experimental science, to the exclusion of theological and metaphysical" [3]. William Whewell, a philosopher and historian of science who so used the term "science" in his Philosophy of the Inductive Sciences (1840), is credited with establishing this meaning. The first recorded use of the idea of the scientist, however, was at the Association for the Advancement of Science in the early 1830 s, when it was proposed as an analogy to the term "artist." Yet the "two cultures" now refers to the divide between the sciences and the literary humanities and frequently excludes what was originally analogized to science-art.

The idea of "two cultures" was a great source of fame for Snow in the 1960s. He received 20 honorary degrees in the course of the decade and, following the Labour Party's election in October 1964, accepted Harold Wilson's invitation to become the second-in-command at the newly established (U.K.) Ministry of Technology, becoming the government spokesman on technology in the House of Lords. From 1966 until his death in 1980, Snow traveled the world as a lecturer, adviser and public sage.

In the second edition of Two Cultures, in 1963, Snow added a new essay, "The Two Cultures: A Second Look." In that essay he suggested that a new "Third Culture" would emerge and close the gap between literary intellectuals and scientists [4]. It is significant to note that Snow originally named his lecture "The Rich and the Poor" and intended this to be the center of his argument: "Before I wrote the lecture I thought of calling it 'The Rich and the Poor,' and I rather wish I hadn't changed my mind" [5]. He remained dissatisfied with the two-cultures concept and on several occasions tried to refine the claim. In his last public statement regarding the topic of "two cultures," he made clear that the larger global and economic issues remained central and urgent to him: "Peace. Food. No more people than the Earth can take. That is the cause" [6].

\section{ART, SCIENCE AND TECHNOLOGY: BUILDING THE TRIANGULAR BRIDGE}


But it seems that there is still much work to be done in building the bridge between the humanities and the sciences. The provocative literary agent John Brockman, editor of a book of essays entitled The Third Culture, negates Snow's optimistic prediction that a day will come when literary intellectuals will communicate effectively with scientists. Instead he claims that contemporary scientists are the third culture and that there is no need for trying to establish communication between scientists and literary intellectuals, whom he calls "middlemen" [8]. Although the choice of people in his book is significant [9], it does indicate the enduring gap between the humanities and sciences and clearly shows that the bridges being constructed are still very fragile.

Brockman also runs a discussion web site, <www.edge.org >, where he continues to promote the idea of a new cultural elite based in the sciences. By default this connects to the computer sciences and the emerging new economy, yet somehow the digital arts do not show up as a component of this emerging cultural elite. Brockman sees that science is a global genre, and recognizes that "we're in a science world; we're in a software world." He has "found that the artists were all reading science. They weren't reading the literary people. The literary people were still fighting the same fights-who was a Trotskyist in 1937? They're still doing it today. These are the people who hijacked the word 'intellectual' in the Thirties from the scientists" [10].

I would argue, however, that artists are not only critical in helping to heal and bridge the painful communication gap, but are in position to play a critical role.

The bridge, in fact, is being triangulated and made more stable with the work of artists utilizing new technologies, who are in active dialogue with both sides. Artists using technology are uniquely positioned in the middle of the scientific and literary/philosophical communities and are allowed poetic license, which gives us the freedom to reinforce the delicate bridge and indeed contribute to the creation of a new, mutant third culture. By utilizing tools familiar to scientists and collaborating with the scientific community, we are getting closer to an atmosphere of collaboration and mutual respect.

This road, however, is not without dangers of which to be wary. It is a delicate mission to be in between disciplines that are themselves in a tenuous rela- tionship. Perhaps the greatest danger is for artists to look to literary, philosophical and theoretical circles for interpretations of scientific data and then further reinterpret these versions without checking back with the scientists. Much postmodern writing borders on linguistic play with mathematical and scientific terminology and serves to alienate the scientific community, which has used precise methods to arrive at those theories [11]. This is not to say that one should blindly accept all products of the scientific community, but simply to suggest that any working relationship needs to be based on mutual respect and dialogue. The other danger that faces those "in between" working on creating "something else" is a general attitude holding theory above practice, prevalent in both the humanities and sciences. At this stage, it is in the practice of art that the freedom lies to make assertions beyond the rational and beyond the necessary methodology of proving a thesis. Practice informed by theory-or, conversely, theory informed by practiceutilizing a methodology accessible to both worlds is the key.

Currently, much of this bridge-building work takes place in universities, for more reasons than one. First, at this point, with no market in place, it is impossible for such artists to make a living outside of academia and industry. Of the two, academia is generally friendlier to someone searching for a yet-tobe-defined path than industry, with its pressures to produce. Second, academia is a natural environment for access to good bandwidth and updated equipment. Third, and perhaps most important, academia allows artists contact with scholars from many disciplines. In order to function and communicate effectively in this context, one must learn the etiquette and language of various disciplines. The challenge, then, is to do this without losing the intuitive, "wild" aspect of artistic practice, which taps into the silent, the unknown, the mysterious.

Our work depends largely on an active dialogue with scientists and humanists while performing the important function of bridge builders. And as any engineer knows, we have to know the territory on both sides and be very precise in how we negotiate the space "in between." Negotiating the gap between the canon of rationality and the fluid poetic is ultimately the goal of artists who work with communication technologies.

\section{The Creative Process of ARTISTS AND SCIENTISTS- THE DISCOVERY OF STRANGENESS}

Any definition of complexity is necessarily context-dependent, even subjective.

$$
\text { -Murray Gell-Mann [12] }
$$

One of the most important scientists to comment on the similarities between artists' and scientists' creative processes, physicist Werner Heisenberg [13], believed that artists' creativity arose out of the interplay between the spirit of the time and the individual. For Marshall McLuhan, artistic inspiration was the process of subliminally sniffing out environmental change: "It's always been the artist who perceives that alterations in man are caused by a new medium, who recognises that the future is the present, and uses his work to prepare ground for it" [14]. In fact both artist and scientist are involved in the work of intuiting change in perception and materializing it for others to experience, see and ultimately change.

\section{SCIENCE AND "SOMETHING ELSE"}

Murray Gell-Mann is the founder of the Santa Fe Institute, where Stuart Kauffman, Per Bak, Roger Penrose and others have studied the possibility of a still-undiscovered law of nature that might explain why the universe has generated so much order in spite of the supposedly universal drift toward disorder decreed by the Second Law of Thermodynamics [15]. This "something else," as Gell-Mann calls it [16], would be located beyond the horizon of contemporary science; it would be something that could better explain the mystery of life, of human consciousness and of existence itself. To Gell-Mann, this indicated a certain tendency toward obscurantism and mystification.

One of the most profound goals of this "chaoplexity" pursued by Kauffman, Bak, John Holland and others is the elucidation of a new law, or set of principles, or unified theory, or something that would make it possible to predict the behavior of a variety of dissimilar complex systems. A closely related proposition is that the universe harbors a complexity-generating force that counteracts the second law of thermodynamics and creates galaxies, life and even life intelligent enough to contem- 
plate itself. How could one not then summon the ancient texts of the Vedas, Buddhism and much of Eastern mysticism? Although Gell-Mann was playing when he referred to the eightfold way and to Finnegan's Wake, he did touch on that something else many disciplines are struggling to define.

\section{END OF ART, END OF SCIENCE?}

I have discovered that the discussion of whether we are reaching the "end" of things is not limited to the field of art. Apparently this is an ongoing and lively discussion in the world of science as well. John Horgan, who spent years profiling major names in the world of science for Scientific American, asks this question in The End of Science (1996) [17]. He investigates a number of disciplines and questions major personalities in each field about whether these disciplines are reaching their limits: philosophy, physics, cosmology, evolutionary biology, chaoplexity, limitology, scientific theology and machine science. Horgan's premise intrigued the world of science and did not go unchallenged. It was publicly denounced by President Clinton's science advisor, the administrator of NASA, a dozen or so Nobel laureates and scores of critics [18]. The simple point Horgan misses is that every end constitutes a new beginning, and by stating doubt that there will be any more Einsteins or Bohrs in the future, he does not take into account the possible emergence of group genius or endless mutations of disciplines that truly do result in something new. Reaching limits in science or any other discipline for that matter really means being on the threshold of the inevitable something else.

\section{REACTING AGAINST "SOMETHING ELSE"}

Transgressing disciplinary boundaries ... [is] a subversive undertaking since it is likely to violate the sanctuaries of accepted ways of perceiving. Among the most fortified boundaries have been those between the natural sciences and the humanities [19].

Contemporary art practice, particularly that utilizing digital technology, is loaded with references to science, and this trend has taken root in cultural theory as well. In fact, an entire new field has been formed in the humanities: science studies. One would think that this would allow for better communication between the sciences and humanities, but in general this does not appear to be the case at present. Some of the work coming out of science philosophy and some theoreticians commenting on the scientific process have infuriated some scientists and actually deepened the gap between the Two Cultures.

The most famous recent case, and in my opinion relevant to consider, is the Sokal affair. In 1996 physicist Alan Sokal published, in the American cultural-studies journal Social Text, a parody entitled "Transgressing the Boundaries: Toward a Transformative Hermeneutics of Quantum Gravity." The article is crammed with "non-sensical quotations about physics and mathematics" by prominent French and American intellectuals such as Lyotard, Derrida, Irigaray and Lacan. The text is full of references to scientists such as Heisenberg, Kuhn, Bohr, Harding, Bell and Gödel and is indeed as difficult to read as any postmodern theoretical text could be. The references cited are all real, and all quotes are rigorously accurate; however, having been taken out of their cultural contexts and reframed, they do assume questionable meanings. According to Sokal, it was meant as an experiment to test whether Sokal's bold assertion (without evidence or argument) that physical reality is at bottom a social and linguistic construct would raise eyebrows among the editors. It did not. The editors trusted that the information in the essay, quoted from established scientists, would be an honest contribution and did not read carefully the erroneous information referred to in the text. The debates sparked by Sokal's hoax have come to encompass a wide range of tenuously related issues concerning not only the conceptual status of scientific knowledge or the merits of French poststructuralism, but also the social roles of science and technology, multiculturalism, and "political correctness," the academic left versus the academic right and the cultural left versus the economic left.

The text was followed by an entire book, Intellectual Impostors, which Sokal co-wrote with Jean Bricmont [20]. In the book they exhibit incredible zeal and thoroughness in their effort to de-mystify these very famous intellectuals. Perhaps the most impressive aspect of this hoax-article-turned-into-event-and-book is the rigor with which the thesis is delivered. One wonders if they actually had to put aside their own scientific research to write this book, which would indicate that this was much more than a hoax but something they felt was very important to deliver to the scientific community and the public at large. There is no question that the authors have done their homework and that their work has had a definite impact on the Two Cultures. Some of the fallout is positive in that it brought to the surface and activated a dialogue that was simmering under the surface. The negative aspects are that the dialogue was colored by controversy and was mostly argumentative, thus endangering the fragile bridge between the humanities and the sciences. Why was Sokal not flattered that science has a such a strong influence on contemporary philosophers, as Einstein was when he read Fuller's interpretation of the Theory of Relativity?

The philosophers that Sokal and Bricmont attack are those working in theory of psychoanalysis, semiotics or sociology and whose work is subject to innumerable analyses, seminars and doctoral theses. It is important to note that Sokal and Bricmont do not mention any authors who are principally literary or poetic. They do make a valid point when saying that scientific terminology and fact have been abused and consequently have served to spread false information. Sokal assembled a list of quotations that showed this kind of handling of the natural sciences and circulated it to his scientific colleagues whose reactions were "a mixture of hilarity and dismay. They could hardly believe that anyone-much less renowned intellectuals-could write such nonsense." Nonscientists who were shown the texts needed lay explanations of why the passages were "meaningless" [21]. One can only imagine the reaction of scientists reading a quote from Lacan in which he refers to the structure of the neutronic subject as "exactly the torus (it is no less a reality itself)," or a passage by Kristeva, stating that poetic language can be theorized in terms of the cardinality of the continuum; or Baudrillard's contention that modern war takes place in non-Euclidean space [22].

We do get a clue that there is more at stake in Dreams of a Final Theory by Steven Weinberg:

These radical critics of science seem to be having little or no effect on scientists themselves. I do not know of any working scientist who takes them seriously. The danger they present to science comes from their possible influence on those who have not shared in 
the work of science but on whom we depend, especially those in charge of funding science and on new generations of scientists [23].

\section{USING POETIC LICENSE AS A TOOL}

No doubt the first act of the calculus consists of "depotentialisation" of the equation (for example, instead of $2 \mathrm{ax}-$ $x 2=y 2$ we have $d y / d x=(a-x / y u))$. However, the analogue may be found in the two preceding figures where the disappearance of quantum and the quantitas was the condition for the appearance of the element of quantitability. ... [ [24]

It is important to note that Sokal and Bricmont are tolerant of the use of scientific terminology in the context of art or science fiction:

If a poet uses the words like "black hole" or "degree of freedom" out of context and without really understanding their scientific meaning, it doesn't bother us. Likewise, if a science fiction writer uses secret passageways in spacetime in order to send her characters back to the era of the Crusades, it is purely a question of taste whether one likes or dislikes the technique [25].

Clearly this points to a semi-favorable position for artists in relation to the sciences, particularly those working with technology. What complicates matters, however, is that many artists are inspired by and interpret the very philosophers that are under attack from the scientific community [26]. What Sokal and Bricmont fail to notice is that absolutely all the authors addressed in their book have become staple philosophers for artists working with media, particularly Deleuze and Guattari, to whom they dedicate an entire chapter analyzing Deleuze and Guattari's misuse of scientific and mathematical terms. On the one hand one could argue that Deleuze and Guattari utilize these scientific and mathematical terms in distinctly metaphorical or philosophical senses, which would explain their vague or tenuous relationship to "hard" scientific fact; this argument is lost, however, when one finds direct quotes and references to a book on the theory of differential equations, in which they use terms such as "singularity" and "singular point" in a distinctly technical and mathematical sense. Deleuze and Guattari, then, use these terms sometimes literally and sometimes metaphorically without distinction or explanation [27]. Although I sympathize with Deleuze and Guattari's approach and can relate to their writ- ings in many ways, I feel that Sokal and Bricmont are flashing an important red light to artists who are inspired by scientific innovation and discovery and are interested in working closely with the scientific community.

\section{THE METHODOLOGY OF "ANYTHING GOES": EMBRACING PARADOX, CONTRADICTION AND RHETORICAL EXCESS}

Much epistemic relativism in philosophy is understood by the scientific community as violent attacks on science. Frequently quoted in discussions about relativism is Paul Feyerabend, who is also analyzed by Sokal and Bricmont. Although acknowledging his complex personality, they write, "Nevertheless, Feyerabend's writings contain numerous ambiguous and confused statements, which sometimes end in violent attacks on science: attacks which are simultaneously philosophical, historical and political, and in which judgements of fact are mixed with judgements of value" [28]. Indeed they find his views, in some extreme cases, to have problems similar to those of the other philosophers they critique. His first and most famous book, Against Method (1975), translated into 16 languages, argued that philosophy cannot provide a methodology and rationale for science since there is no rationale to explain. Particularly inflammatory was his famous "Anything Goes" statement: "All Methodologies have their limitations and the only 'rule' that survives is 'anything goes'" [29]. In a footnote, Feyerabend suggests that if we assume that science and art share a problem-solving attitude, the only significant difference between them would disappear; therefore, we could speak of "styles and preferences for the former, and progress for the latter" [30].

\section{SHARING THE LANGUAGE: COLlabORATION}

Perhaps the source of these communication problems can be traced to the fact that most of the philosophers under attack in the scientific community do not work closely with scientists and that scientists are equally isolated from the movements of philosophical thought and contemporary artistic expression. As long as a work does not have a reason to be located in a few disciplines simultaneously, room for misunderstandings will be ample. The work of artists working with technology demands interaction with scholars from a wide variety of disciplines such as computer science, social studies, philosophy and cultural studies. Bridging and synthesizing many worlds while composing "something else" becomes the art.

\section{References and Notes}

1. M. Kleine, Mathematics in Western Culture (1977) pp. 157-158.

2. C.P. Snow, Two Cultures and the Scientific Revolution (Cambridge, U.K.: Cambridge Univ. Press, 1964) p. xii.

3. Snow [2] p. xi.

4. C.P. Snow, Two Cultures and the Scientific Revolution (Cambridge, U.K.: Cambridge Univ. Press, 1963) p. 53.

5. Snow [2] p. 79.

6. Snow (1968) p. 220.

7. R.B. Fuller, Critical Path (New York: St Martin's Press, 1981) p. 27.

8. J. Brockman, The Third Culture: Beyond the Scien tific Revolution (New York: Simon and Schuster 1995) p. 18.

9. Representatives of the Third Culture, according to Brockman, include William C. Williams Stephen Jay Gould, Richard Dawkins, Brian Goodwin, Steve Jones, Niles Eldredge, Lynn Margulis, Marvin Minsky, Roger Schank, Daniel C. Dennett, Nicholas Humphrey, Francisco Varela, Steven Pinker, Roger Penrose, Martin Rees, Alan Guth, Lee Smolin, Paul Davies, Murray Gell-Mann Stuart Kauffman, Christopher G. Langton, J Doyne Farmer and W. Daniel Hillis. He first published a brief essay on the idea of the emerging third culture in September 1991 in his journal, The Edge. See also <www.edge.org/3rd_culture>.

10. Marek Kohn, "Laboratories against the Literati: John Brockman Is the Agent Who Made Top Scientists Sexy-And He Loathes the Ignorant Literary World,"<http://www.edge.org/documents independent.html $>24$ March 2000.

11. The term "postmodern" is being used as summarized by Barry Smart:

Postmodernity remains a contentious term, signifying for some analysts simply a "symptom of the current mood of Western intelligentsia" [A. Callinicos, Against Postmodernism: A Marxist Critique (New York: St. Martin's Press, 1989) p. 9], whilst for others it describes important aspects of the social, cultural, and political conditions to which we increasingly find ourselves subject. [D. Harvey, The Condition of Postmodernity: An Enquiry into the Origins of Cultural Change (Oxford, U.K.: Blackwell, 1989); Z. Bauman, Intimations of Postmodernity (London: Routledge, 1992)] And of those analysts who regard the term as appropriate for describing contemporary conditions some at least clearly consider the constituency affected, the "we," not to be confined to either the "first" world or the intelligentsia alone. The configuration of Western modernity has been placed in question and challenged in a second, somewhat different manner by increasing evidence that the economic and cultural momentum has swung away from both Europe and America towards the Pacific rim and the modernising societies of the East.

-B. Smart, Postmodernity: Key Ideas

(New York: Routledge, 1993) pp. 150-151.

12. M. Gell-Mann, The Quark and the Jaguar (New York: W.H. Freeman, 1994) p. 33. 
13. W. Heisenberg, Physics and Philosophy (London: Penguin, 1968).

14. M. McLuhan with H. Parker, Counterblast (New York: Harcourt, Brace, 1969).

15. This is the law of nature that says that things wear out. One expression of the Second Law of Thermodynamics is that heat cannot flow from a cold object to a hotter object of its own volition. Place an ice cube in a cup of warm water and the ice melts as heat flows into it from the water, resulting in a cup of slightly cooler water than you had before. You never see ice cubes spontaneously forming in cups of water, as heat drains out of the cold ice into the hotter liquid. Ice cubes can only be made (for example, in a domestic refrigerator) by using energy to pump heat out. Another facet of the Second Law is the way in which a house left unattended will crumble away under the influence of wind and weather, whereas a pile of bricks left unattended will never spontaneously form itself into a house. J. Gribbin, Q Is for Quantum: An Encyclopedia of Particle Physics (New York: The Free Press, 1998) p. 359.

16. J. Horgan, The End of Science: Facing the Limits of Knowledge in the Twilight of the Scientific Age (New York: Broadway Books, 1997) p. 214.

17. One could easily compile a list of disciplines in the humanities and ask this same question, with the difference of having a bit more representation of women and minority opinion. Horgan's book does not list one woman or minority as a major authority, which could be a good sign if he is announcing the end of the world as we know it.

18. J. Horgan [16] p. 267.

19. V. Greenberg, Transgressive Readings: The Texts of Franz Kafka (Ann Arbor, MI: Univ. of Michigan Press, 1990).

20. J. Bricmont and A. Sokal, Intellectual Imposters: Postmodern Philosophers' Abuse of Science (London: Profile Books, 1997) p. 19.

21. Bricmont and Sokal [20] p. 3.

22. Bricmont and Sokal [20] p. 137.

23. S. Weinberg, Dreams of a Final Theory (New York: Pantheon, 1992).

24. G. Deleuze, Difference and Repetition, P. Patton, trans., (New York: Columbia Univ. Press, 1994) pp. 174-175; Bricmont and Sokal [20] p. 213.
25. Sokal and Bricmont [20] p. 8 .

26. See list of conferences that have been organized around discussions of the work of Deleuze and Guattari: <http:// lists.village.virginia.edu/ $\sim$ spoons/d-g_html/>. For artists inspired by science, see Wellcome Trust's SCI ART initiative, 1998, and Art and Science Collaborations, Inc.: $<$ http://www.asci.org $>$.

27. Bricmont and Sokal [20] p. 216; Deleuze [24] pp. 50, 54, 339-340n

28. Bricmont and Sokal [20] p. 73.

29. P. Feyerabend, Against Method (London: Verso, 1975) p. 296.

30. Feyerabend [29] p. 197. What is intriguing about Feyerabend is his embrace of paradox, contradiction and rhetorical excess. He is another complex persona, who as a teenager studied opera and astronomy simultaneously and envisioned himself working in both fields. Later he went back and forth between majors in physics and philosophy, eventually settling on the latter. Feyerabend studied under Karl Popper at the London School of Economics, where he met Imre Lakatos, who urged him to write Against Method. He then moved to Berkeley, California, where he befriended Thomas Kuhn and strongly rejected the superiority of science to other modes of knowledge and as a result was labeled by many as an anti-scientist.

\section{Bibliography}

Albert, M. "Not All Stories Are Equal: Michael Albert Answers the Pomo Advocates." Z Papers Special Issue on Postmodernism and Rationality <http:// www.zmag.org/ScienceWars/notallstories.htm> (1996)

Albert, M. "Science, Postmodernism and the Left," Z Magazine 9, No. 7-8 (July/August 1996).

Bateson, G. Steps to an Ecology of Mind (1972).

Baudrillard, J. The Gulf War Did Not Take Place, P. Patton, trans. (Bloomington, IN: Indiana Univ. Press, 1995)

Bricmont, J. "Science of Chaos or Chaos of Science?” Physicalia Magazine 17, No. 3-4 (1995); available online as publication UCL-IPT-96-03 <http:// www.fyma.ucl.ac.be/reche/1996/1996.html $>$.
Bohm, D. “On Creativity," Leonardo 1, No. 2, p. 177 (1968).

Chomsky, N. "Rationality/Science," Z Papers Special Issue on Postmodernism and Rationality <http://www.zmag.org/zmag/articles chomopomoart.html> (1992-1993).

Cringeley, Robert X. Accidental Empires: How the Boys in Silicon Valley Make Their Millions, Battle Foreign Competition, and Still Can't Get a Date (New York: Harper Business, 1996).

Feyerabend, P. "Theoreticians, Artists and Artisans," Leonardo 29, No. 1, 23-28 (1996)

Foresta, D. "The Many Worlds of Art, Science and the New Technologies," Leonardo 24, No. 2, 139144 (1991).

Hertz, G. "The Godfather of Technology and Art: An Interview with Billy Kluver," (19 April 1995 <www.conceptlab.com/interviews/kluver.html>.

Johnson, G. Fire in the Mind: Science, Faith and the Search for Order (New York: Knopf, 1995)

Kauffman, Stuart. At Home in the Universe: The Search for Laws of Self Organization and Complexity (New York: Oxford Univ. Press, 1995).

Lovejoy, M. Postmodern Currents (Ann Arbor, MI: Michigan Univ. Press, 1989).

Smart, B. Postmodernity: Key Ideas (New York: Routledge, 1993).

Snow, C.P. Two Cultures (Cambridge, U.K.: Cambridge Univ. Press, 1959).

Sokal, A. "Transgressing the Boundaries: Towards a Transformative Hermeneutics of Quantum Gravity," Social Text No. 46/47 (Spring/Summer 1996).

Supple, C. 1996. "5 Americans Share Nobels for Science: New Structures Found in Chemistry, Physics," The Washington Post (10 October 1996).

Theocharis, T. and Psimopolous, M. "Where Science Has Gone Wrong,” Nature 29 (15 October 1987).

Manuscript received 10 June 2000 . 
http://www.jstor.org

\title{
LINKED CITATIONS \\ - Page 1 of 1 -
}

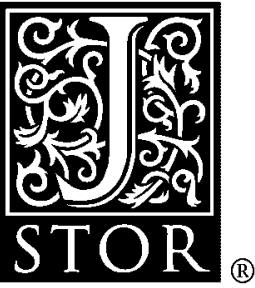

You have printed the following article:

Toward a Third Culture: Being in between

Victoria Vesna

Leonardo, Vol. 34, No. 2. (2001), pp. 121-125.

Stable URL:

http://links.jstor.org/sici?sici=0024-094X\%282001\%2934\%3A2\%3C121\%3ATATCBI\%3E2.0.CO\%3B2-3

This article references the following linked citations. If you are trying to access articles from an off-campus location, you may be required to first logon via your library web site to access JSTOR. Please visit your library's website or contact a librarian to learn about options for remote access to JSTOR.

\section{Bibliography}

\author{
On Creativity \\ D. Bohm \\ Leonardo, Vol. 1, No. 2. (Apr., 1968), pp. 137-149. \\ Stable URL: \\ http://links.jstor.org/sici?sici=0024-094X\%28196804\%291\%3A2\%3C137\%3AOC\%3E2.0.CO\%3B2-S
}

\section{Theoreticians, Artists and Artisans}

Paul Feyerabend

Leonardo, Vol. 29, No. 1. (1996), pp. 23-28.

Stable URL:

http://links.jstor.org/sici?sici=0024-094X\%281996\%2929\%3A1\%3C23\%3ATAAA\%3E2.0.CO\%3B2-Z

\section{The Many Worlds of Art, Science and the New Technologies}

Don Foresta

Leonardo, Vol. 24, No. 2, Connectivity: Art and Interactive Telecommunications. (1991), pp. 139-144.

Stable URL:

http://links.jstor.org/sici?sici=0024-094X\%281991\%2924\%3A2\%3C139\%3ATMWOAS\%3E2.0.CO\%3B2-4

\section{Transgressing the Boundaries: Toward a Transformative Hermeneutics of Quantum Gravity}

Alan D. Sokal

Social Text, No. 46/47, Science Wars. (Spring - Summer, 1996), pp. 217-252.

Stable URL: 